\title{
HEALTH-RELATED QUALITY OF LIFE AND POST-TRAUMATIC STRESS DISORDER IN PATIENTS AFTER CARDIAC SURGERY AND INTENSIVE CARE TREATMENT
}

Christian Stoll, MD

Gustav Schelling, MD ${ }^{\mathrm{a}}$

Alwin E. Goetz, MD

Erich Kilger, MD

Andreas Bayer ${ }^{\mathrm{a}, \mathrm{b}}$

Hans-Peter Kapfhammer, MD $^{\mathrm{c}}$

Hans-Bernd Rothenhäusler, MD $^{c}$

Eckart Kreuzer, MD ${ }^{\mathrm{b}}$

Bruno Reichart, $\mathrm{MD}^{\mathrm{b}}$

Klaus Peter, $\mathrm{MD}^{\mathrm{a}}$
Objectives: Health-related quality of life and patient satisfaction have become important end points in cardiac surgery. Post-traumatic stress disorder has been described in patients with life-threatening heart disease. In this study, we investigated the occurrence of post-traumatic stress disorder in a sample of patients after cardiac surgery and compared health-related quality of life and patient satisfaction between patients with and without evidence of post-traumatic stress disorder.

Methods: We studied 80 patients serially admitted to the intensive care unit after cardiac surgery (bypass grafting, $\mathrm{n}=51$; aortic valve replacement, $\mathrm{n}=$ 29). Health-related quality of life was assessed with the use of the SF-36 Health Status Questionnaire. Post-traumatic stress disorder was measured with a previously validated instrument (the Post-Traumatic Stress Syndrome 10-Questions Inventory), and 20 different aspects of life satisfaction were quantified on a scale ranging from 0 to 10 . For measurements of health-related quality of life and post-traumatic stress disorder, age- and gender-comparable healthy individuals, as well as patients with cardiovascular diseases, served as control groups.

Results: Patients who had cardiac surgery described high life satisfaction summary scores (156 of a maximum of 200 points) and only small impairments in physical and mental SF-36 summary scores when compared with healthy control groups (median reduction 7.15, $P<.05$ ). Patients with evidence of post-traumatic stress disorder $(n=15)$ reported the lowest SF-36 mental health summary scores when compared with patients without stress disorder (38.3 vs 48.4, $P=.004)$ and rated their life satisfaction lower (121.5 vs $162.0, P=.002)$.

Conclusions: Patients who have had cardiac surgery demonstrate a high life satisfaction with an acceptable degree of physical and mental health-related quality of life. Impairments in psychosocial function and life satisfaction were found in a subgroup of patients with evidence of post-traumatic stress disorder. (J Thorac Cardiovasc Surg 2000;120:505-12)
From the Departments of Anaesthesiology, ${ }^{\mathrm{a}}$ Cardiac Surgery, ${ }^{\mathrm{b}}$ and Psychiatry, ${ }^{\mathrm{c}}$ Ludwig-Maximilians University, Munich, Germany.

This study was supported by a grant from Hoffman-La Roche, Grenzach-Wyhlen, the Lilly Foundation, and the Techniker Krankenkasse, all in Germany.

Received for publication May 28, 1999; revisions requested Nov 23, 1999; revisions received April 26, 2000; accepted for publication April 26, 2000.

Address for reprints: Christian Stoll, MD, Department of Anaesthesiology, Klinikum Grosshadern, Ludwig-Maximilians University, 81377 Munich, Germany (E-mail: christian.stoll@ana.med.uni-muenchen.de).

Copyright (C) 2000 by The American Association for Thoracic Surgery

0022-5223/2000 $\$ 12.00+0 \quad \mathbf{1 2 / 1 / 1 0 8 1 6 2}$

doi: $10.1067 / \mathrm{mtc} .2000 .108162$
D espite considerable progress in surgical management of cardiac disease, relatively little is known about physical and social determinants of quality of life in survivors. Although mortality of cardiac surgery is now significantly lower than that observed in the $1970 \mathrm{~s},{ }^{1}$ traditional outcomes like mortality and morbidity are no longer fulfilling the demand for data evaluating a patient's life after a specific medical intervention. A possible way to answer this question is the measurement of health-related quality of life (HRQL) after discharge from the hospital in patients who have had cardiac surgery. HRQL is a multidimensional concept and represents an important secondary outcome in intensive 
Table I. Diagnostic criteria of PTSD

A. The person has been exposed to a traumatic event in which both of the following have been present:

1. The person has experienced, witnessed, or been confronted with an event or events that involve actual or threatened death or serious injury, or a threat to the physical integrity of self or others.

2. The person's response involved intense fear, helplessness, or horror.

B. The traumatic event is persistently re-experienced in one (or more) of the following ways:

1. Recurrent and intrusive distressing recollections of the event, including images, thoughts, or perceptions

2. Recurrent distressing dreams of the event

3. Acting or feeling as if the traumatic event were recurring

4. Intense psychologic distress at exposure to internal or external cues that symbolize or resemble an aspect of the traumatic event

5. Physiologic reactivity on exposure to internal or external cues that symbolize or resemble an aspect of the traumatic event

C. Persistent avoidance of stimuli associated with the trauma and numbing of general responsiveness (not present before the trauma), as indicated by three (or more) of the following:

1. Efforts to avoid thoughts, feelings, or conversations associated with the trauma

2. Efforts to avoid activities, places, or people that arouse recollections of the trauma

3. Inability to recall an important aspect of the trauma

4. Markedly diminished interest or participation in significant activities

5. Feeling of detachment or estrangement from others

6. Restricted range of affect (eg, unable to have loving feelings)

7. Sense of a foreshortened future (eg, does not expect to have a career, marriage, children, or a normal life span)

D. Persistent symptoms of increased arousal (not present before the trauma), as indicated by two (or more) of the following:

1. Difficulty falling or staying asleep

2. Irritability or outbursts of anger

3. Difficulty concentrating

4. Hypervigilance

5. Exaggerated startle response

E. Duration of the disturbance (symptoms in criteria B, C, and D) is more than 1 month.

F. The disturbance causes clinically significant distress or impairment in social, occupational, or other important areas of functioning.

Diagnostic criteria of PTSD according to the Diagnostic and Statistical Manual of Mental Disorders of the American Psychiatric Association (DSMIV). ${ }^{10}$ The condition is termed chronic when present for more than 3 months.

care $^{2}$ and medicine in general. ${ }^{3}$ Although methodologically difficult to measure, validated instruments for evaluation of HRQL are available ${ }^{4}$ and were used in survivors of intensive care ${ }^{5,6}$ and in patients after cardiac surgery. ${ }^{7}$

Severe cardiac disease like myocardial infarction or the symptoms of angina pectoris are often perceived by the individual as a life-threatening and devastating event. The knowledge of the need for the imminent operation contributes to the perceived physical and psychologic stress. Anesthesia, surgery, and car- diopulmonary bypass are strong physical and emotional stressors, and psychologic or neurologic alterations are often observed in patients after cardiac surgery. ${ }^{8}$ After the operation, the patients are transferred to the intensive care unit (ICU), where they are subjected to weaning from mechanical ventilation, early extubation, and mobilization. High-technology intensive care has an important role in the improvement in mortality and morbidity in this field. However, along with the severe underlying disease process, that same ICU environment can confer extreme physical and mental stress; anxiety, pain, respiratory distress, and nightmares are often reported after ICU treatment. ${ }^{6}$ Whether the prolonged exposure to these combined stressors results in long-lasting negative effects on emotional well-being, mental health, or HRQL is currently unknown.

Post-traumatic stress disorder (PTSD) is the development of characteristic symptoms after exposure to extreme stress. Events that trigger PTSD involve experiencing a serious threat to one's own physical integrity that is accompanied by intense fear, horror, and helplessness. ${ }^{9}$ Diagnostic criteria for PTSD include a history of exposure to one or more traumatic events and symptoms from each of 3 symptom clusters: intrusive recollections, avoidance/numbing symptoms, and hyperarousal symptoms ${ }^{10}$ (Table I). Patients with PTSD showed significant impairments in psychosocial functioning in a recent study in survivors of ICU treatment, ${ }^{6}$ and PTSD has been described in patients after cardiac events. ${ }^{11}$

This study was designed to assess HRQL in patients after coronary artery bypass grafting (CABG) or aortic valve replacement (AVR) to describe the prevalence of PTSD and to analyze the relationship between PTSD, HRQL, and patient satisfaction after cardiac surgery.

\section{Methods}

Patient selection and definition of the study group. All adult patients (age $>16$ years) treated by the Department of Cardiac Surgery at the Klinikum Großhadern, the tertiary care center of the Ludwig-Maximilians University, Munich, who underwent $\mathrm{CABG}$ or AVR and were discharged between October 1 and November 31, 1997, were eligible for enrollment. Indications for $\mathrm{CABG}$ were angina resistant to medical therapy and not appropriate for cardiologic intervention. Patients with poor left ventricular function (ejection fraction $<25 \%$ ) and combined valvular and coronary disease were excluded. Patients were considered for AVR when a pressure gradient greater than $50 \mathrm{~mm} \mathrm{Hg}$ or an orifice area less than $1 \mathrm{~cm}^{2}$ was present in patients with aortic stenosis or in symptomatic patients with aortic regurgitation with an end-diastolic volume index greater than $160 \mathrm{~mL} / \mathrm{m}^{2}$, an end-systolic volume index greater than $90 \mathrm{~mL} / \mathrm{m}^{2}$, or an 
ejection fraction less than $45 \%$. Patients with acute endocarditis or those undergoing emergency procedures were excluded. For all patients having CABG or AVR, the same type of cardiopulmonary bypass, involving use of membrane oxygenators associated with moderate hypothermia $\left(32^{\circ} \mathrm{C} \pm 0.2^{\circ} \mathrm{C}\right)$, was performed. Pump flow during cardiopulmonary bypass was adjusted to maintain a mean arterial pressure of more than $60 \mathrm{~mm} \mathrm{Hg}$ and a minimal flow rate of $2.4 \mathrm{~L} \cdot \mathrm{min}^{-1} \cdot \mathrm{m}^{-2}$ body surface area. Myocardial protection was achieved by infusion of cold hyperkalemic cardioplegic solution (Bretschneider solution).

Eligible patients were identified by means of a computerized documentation system that provided the following data: type of surgical procedure (AVR or CABG), all necessary data to calculate the preoperative Clinical Severity Score for Coronary Artery Disease (CSS) according to Higgins and associates, ${ }^{12}$ and the Simplified Acute Physiology Score (SAPS II) ${ }^{13}$ on admission to the ICU, duration of mechanical ventilation and ICU treatment, and 30 day survival/nonsurvival.

The study was approved by the local institutional review board and data protection met the standard set by German law. Eligible patients were initially contacted by telephone and received a detailed explanation of the purpose of the study. A standard text was used for this initial approach and, after informed oral consent, the patients were mailed questionnaires assessing HRQL, the incidence and intensity of PTSD, and patient satisfaction.

HRQL. HRQL was measured with the self-administered Medical Outcomes Study Short Form Survey that consists of 36 questions (SF-36) and covers 8 basic health concepts: physical function, social function, physical role function, emotional role function, mental health, pain, vitality, and general health perception. ${ }^{14}$ The measurement model underlying the construction of the SF-36 scales includes items and 8 scales that aggregate 2 to 10 items each. All but 1 of the 36 items are used to score the 8 SF- $36^{*}$ scales. $^{15}$ In addition, summary scores for physical and mental health can be calculated. ${ }^{16}$ A score ranging from 0 to 100 is calculated for the 8 scales, with higher scores indicating a better HRQL. Published reliability statistics of the SF-36 have exceeded 0.80 in most studies (a minimum standard of 0.70 is recommended for measures used in group comparisons). ${ }^{6,15}$ Clinical studies have shown that the physical scales of the SF36 (physical functioning, role-physical, and bodily pain) tend to be responsive to the benefits of heart valve surgery. ${ }^{17}$ Likewise, the mental health scales (mental health, role-emotional, social functioning, and vitality) have been shown to be responsive in comparison with patients with and without PTSD. ${ }^{6}$ The SF-36 has been validated in patients after ICU treatment, ${ }^{18}$ and a recent study has demonstrated that differences in angina severity as measured by the Canadian Cardiovascular Society Classification were related to subscales of the SF-36. ${ }^{19}$ A psychometrically validated German translation of the SF-36 was used in patients having cardiac surgery and in control subjects. ${ }^{4}$

*The SF-36 health transition item was not assessed in this study.
Control groups for HRQL measurements. For the purpose of this study, we generated 4 different control groups that were identical to the cardiac surgical patients under study with regard to number, age, sex, and home country (West Germany). Control subjects were selected from a large database $(n=3000)$ used to provide standard values for the SF-36 in a German population. HRQL control group 1 represented age- and sex-identical healthy subjects (defined as healthy, age- and sex-identical individuals without evidence of cardiovascular disease, diabetes, hypertension, or cancer). Control group 2 consisted of medically treated patients with a recent myocardial infarction $(<1$ year), HRQL control group 3 represented individuals with medically treated chronic stable angina, and HRQL control group 4 consisted of patients with a moderate degree of heart failure (New York Heart Association class II-III). These 4 control groups were generated to simplify the interpretation of results and to allow a comparison of HRQL between patients who have had cardiac surgery, normal subjects, and patients with chronic, medically treated cardiovascular diseases.

PTSD. PTSD was measured by means of a modified German version of the Post-Traumatic Stress Syndrome 10Questions Inventory (PTSS-10), a self-report scale originally based on the Diagnostic and Statistical Manual Criteria (DSM), third edition, criteria of The American Psychiatric Association for PTSD. The instrument was originally introduced as a screening test to determine PTSD cases in the aftermath of a disaster and in victims of torture. ${ }^{20}$ This questionnaire records the presence and intensity of 10 post-traumatic stress symptoms: sleep disturbance, nightmares, depression, hyperalertness, withdrawal (emotional numbing and inability to care for others), generalized irritability, frequent changes in mood, guilt, avoidance of activities prompting recall of possible traumatizing events, and increased muscle tensions. When completing the questionnaire, the patients rate their symptoms on a scale from 1 (never) to 7 (always), and a sum score ranging from 10 to 70 points is calculated.

The questionnaire has been validated in patients with PTSD after prolonged ICU treatment by means of a double-blind interview technique performed by psychiatrists. These investigations found an optimal cutoff score of 35 points of the questionnaire for diagnosis of PTSD. The sensitivity of the instrument at this threshold value was 0.77 (95\% confidence interval $0.54-1.0$ ), specificity was 0.97 (95\% confidence interval 0.91-1.00), positive predictive value was 0.91 (95\% confidence interval $0.74-1.00$ ), negative predictive value was 0.93 (95\% confidence interval $0.85-1.00)$, and accuracy was $0.92 .^{21}$

Comparison groups for PTSD measurements. Individuals from PTSD comparison groups completed the same PTSD questionnaire as the cardiac surgical group. PTSD comparison group I $(n=80)$ represented patients after major maxillofacial surgery. This group contained patients treated for tumors and was selected because it represents sick hospitalized patients who require perioperative intubation and mechanical ventilation but almost never experience ICU treatment and should therefore have a lower total stress exposure. PTSD comparison group II $(n=80)$ consisted of healthy 
Table II. Degree of satisfaction with daily life

\begin{tabular}{rlr}
\hline Item & \multicolumn{1}{c}{ Definition } & \\
No. & \multicolumn{1}{c}{ Score $^{*}$} \\
\hline 1 & State of health & $7(5-8)$ \\
2 & Physical fitness & $6(4-8)$ \\
3 & Mental fitness & $8(6-9)$ \\
4 & Personal well-being & $7(5-9)$ \\
5 & Self-esteem & $8(7-9)$ \\
6 & Ability to relax & $8(5-9)$ \\
7 & Success and being accepted by others & $8(5-9)$ \\
8 & Support and feeling of security from others & $8(7-10)$ \\
9 & Independence & $9(7-10)$ \\
10 & Marriage/partnership & $7(5-9)$ \\
11 & Sex life & $7(5-9)$ \\
12 & Family life & $9(8-10)$ \\
13 & Friendship/acquaintances & $8(7-10)$ \\
14 & Professional situation & $8(5-9)$ \\
15 & Financial situation & $8(6-9)$ \\
16 & Housing situation & $9(8-10)$ \\
17 & Leisure time & $9(7-10)$ \\
18 & Medical treatment & $9(8-10)$ \\
19 & How I deal with my illness & $8(6-9)$ \\
20 & Life in general & $8(7-9)$ \\
21 & Summary score & $156(124-176)$ \\
& &
\end{tabular}

Degree of satisfaction with 20 different aspects of daily life in patients after cardiac surgery. The patients assigned a score ranging from 0 to 10 to each item, with a higher score indicating a higher degree of satisfaction.

"Values are median and proportions (first quartile-third quartile).

individuals without known acute or chronic diseases. For reasons of sample composition, individuals from both PTSD comparison groups were generally younger than the cardiac surgical patients under study. Unlike HRQL controls, patients and the comparison group in the PTSD part of this study were therefore only age and sex comparable but not identical.

Patient satisfaction. Patient satisfaction with 20 different aspects of daily life (ranging from satisfaction with health status to life in general, see Table II for item definitions), including contentment with surgical treatment, was evaluated with the aid of a specially designed questionnaire. When completing this instrument, the patients rate their degree of satisfaction with each item on a scale from 0 (no satisfaction at all) to 10 (maximal satisfaction); in addition, a sum score ranging from 0 to 200 can be calculated.

Statistical analysis. Scoring for the SF-36 questionnaire and imputation for missing SF-36 items were performed according to the guidelines provided in the German SF-36 manual. ${ }^{4}$ The Mann-Whitney $U$ test was applied to compare continuous data between patients undergoing CABG or AVR. The nonparametric Kruskal-Wallis analysis of variance on ranks test was used for comparison of SF-36 and PTSD scores between cardiac surgical patients and all controls. Dunn's post hoc test for multiple comparisons was applied to determine which groups were significantly different. The nonparametric Spearman correlation coefficient was calculated as a measure of linear association between variables.
Table III. Patient characteristics and treatment data of the study sample

\begin{tabular}{lccc}
\hline & \multicolumn{2}{c}{ Surgical procedure } & \\
\cline { 2 - 3 } \multicolumn{1}{c}{$\begin{array}{c}\text { Patient and } \\
\text { treatment data }^{*}\end{array}$} & $(n=51)$ & $\begin{array}{c}\text { AVR } \\
(n=29)\end{array}$ & P value \\
\hline Patient data & & & \\
$\quad$ Age (y) & $66(58-72)$ & $61.5(55-70.3)$ & .319 \\
Male/female & $45 / 6^{\dagger}$ & $19 / 10$ & .017 \\
SAPS II & $23(19-29)$ & $22.5(19-34)$ & .694 \\
CSS & $1(1-2)^{\dagger}$ & $2(1-4)$ & .027 \\
TISS & $83.5(74-101)$ & $87.5(81-94)$ & .338 \\
Time interval ${ }^{\ddagger}$ (wk) & $20(18-21)$ & $20(12-19)$ & .122 \\
Treatment data & & & \\
$\quad$ Duration of postop & $11.5(9-17)$ & $12.0(8-16)$ & .283 \\
$\quad$ mechanical ventilation (h) & & & \\
Duration of ICU treatment (d) & $2(1-3)$ & $2(1-2)$ & .992 \\
\hline
\end{tabular}

$C A B G$, Coronary artery bypass grafting; $A V R$, aortic valve replacement; SAPS II, Simplified Acute Physiology Score when admitted to the intensive care unit $(\text { ICU })^{13}$; CSS, Clinical Severity Score ${ }^{12}$; TISS, Therapeutic Intervention Scoring System (a higher score indicates a higher number of interventions and a more complicated postoperative course).

*Values are median (25th-75th percentiles).

Indicates a significant difference when compared with patients undergoing aortic valve replacement.

Denotes the time interval between discharge from the hospital and HRQL and PTSD measurements.

Discrete variables were compared between groups by the $\chi^{2}$ test. We performed stepwise regression analyses to determine those patient or treatment variables that best explained variations in PTSD and SF-36 HRQL scores.

Backward elimination was used to be able to include all variables that were collected because we believed them to be important explanatory variables. Unimportant variables were then removed until all remaining variables contributed significantly. ${ }^{22}$ Results are expressed as medians and ranges or proportions, as appropriate. All statistical calculations were performed with the SPSS statistical package (SPSS Inc, Chicago, Ill).

\section{Results}

Patient selection and study group. A total of 111 patients underwent CABG $(n=71)$ or AVR $(n=40)$ during the study interval. Nineteen patients had to be excluded from analysis because of incomplete or missing data and 3 patients (3.3\%) died after discharge from the hospital. Eighty-nine patients were successfully contacted. Nine patients known to be alive did not return the questionnaires or provided incomplete data. Completed questionnaires were finally available from 80 patients (75\% of all eligible alive patients). Fiftyone of these patients (63.8\%) had undergone CABG and $29(36.3 \%)$ AVR. Patient and treatment data of the final study group are summarized in Table III. HRQL 
Table IV. Comparison of SF-36 HRQL scores among the groups in this study

\begin{tabular}{|c|c|c|c|c|c|}
\hline $\begin{array}{l}\text { SF-36 health } \\
\text { dimension }\end{array}$ & $\begin{array}{l}\text { Cardiac surgery } \\
\text { (index patients) }\end{array}$ & $\begin{array}{l}\text { Healthy subjects } \\
\text { (control group 1) }\end{array}$ & $\begin{array}{c}\text { Myocardial infarction } \\
\text { (control group 2) }\end{array}$ & $\begin{array}{c}\text { Stable angina } \\
\text { (control group 3) }\end{array}$ & $\begin{array}{c}\text { Moderate heart failure } \\
\text { (control group 4) }\end{array}$ \\
\hline General health & $57 \quad(47-72)$ & $(55-82)$ & $43^{*}(30-53)$ & $42^{*}(28-62)$ & $45^{*}(33-56)$ \\
\hline Physical function & $75 \quad(60-89)$ & $(75-100)$ & $65 \quad(40-80)$ & $70 \quad(40-85)$ & $70(40-80)$ \\
\hline Physical role function & $50 \quad(0-75)$ & $(75-100)$ & $13 \quad(0-75)$ & $50 \quad(0-50)$ & $50 \quad(0-100)$ \\
\hline Pain & $68 \quad(41-84)$ & $(52-100)$ & $41^{*}(22-74)$ & $52 \quad(41-74)$ & $51 \quad(32-84)$ \\
\hline Mental health & $76 \quad(60-84)$ & $(68-88)$ & $58^{*}(45-76)$ & $74 \quad(52-84)$ & $68 \quad(50-78)$ \\
\hline Emotional role function & $(0-33)$ & $100 * \quad(100-100)$ & $100 \quad(0-100)$ & $100 *(67-100)$ & $100 *(34-100)$ \\
\hline Social function & $87 \quad(63-100)$ & $(88-100)$ & $88 \quad(63-88)$ & $88 \quad(75-100)$ & $88 \quad(63-100)$ \\
\hline Vitality & $58 \quad(41-70)$ & $(55-75)$ & $40^{*}(30-55)$ & $50 \quad(35-64)$ & 45 (40-65) \\
\hline
\end{tabular}

Comparison of SF-36 health-related quality of life scores between patients after cardiac surgery, healthy subjects (HRQL control group 1), patients after a recent myocardial infarction (treated medically, HRQL control group 2), medically treated stable angina (HRQL control group 3), and patients with a moderate degree of heart failure (New York Heart Association class II-III, HRQL control group 4). All control groups were identical to the group of index patients with regard to number, age, and sex.

*Indicates a significant difference when compared with patients after cardiac surgery $(P<.05$, Kruskal-Wallis test with Dunn's correction). Values are median and 25 th and 75 th percentiles. Higher SF-36 scores represent a superior health-related quality of life. (Note: lower SF-36 pain scores indicate a higher incidence and intensity of pain).

and PTSD were measured a median of 20 weeks (range 18-26 weeks) after discharge from the hospital.

HRQL. No significant difference was noted between patients undergoing CABG or AVR with regard to physical (44.2 vs $43.0, P=.721)$ or mental summary scores (48.4 vs $45.7, P=.174$ ). The majority of patients having cardiac surgery reported a relatively high level of perceived HRQL with relatively high summary scores for physical and mental health of 43.5 (first quartile, 38.3; third quartile, 49.8) and 47.8 (first quartile, 38.7; third quartile, 57.1). Index patients reported particular high median values in the physical, social function, or mental health subscales of the SF-36 (75.0, 87.0 , or 76.0 , respectively).

When patients after cardiac surgery were compared with age- and sex-identical healthy controls (HRQL control group 4), differences emerged both in the physical and mental domains of the SF-36. Patients after cardiac surgery reported somewhat lower values regarding summary scores of physical function (difference of median values between patients after cardiac surgery and healthy controls: $7.90, P<.05)$ and mental health (difference of median values: $6.40, P<.05$, Table IV). There was, however, no significant difference between perception of general health (differences of medians: $10, P>.05)$ and the prevalence and intensity of chronic pain (differences of medians: $-16,{ }^{*}$ $P>.05)$ between patients after cardiac surgery and healthy controls. However, index patients described significantly better physical function than patients after a recent myocardial infarction (difference of median values between patients after cardiac surgery and after

*Note: Higher SF-36 pain scores indicate lower physical pain. myocardial infarction: 6.01, $P<.05$ ). Chronic pain was significantly more common in patients after a recent myocardial infarction (differences of medians: -27 , $P<.05)$. Patients after cardiac surgery had significantly higher mental health and vitality scores than patients after a recent myocardial infarction (differences of medians: 18 and 17.5, respectively, $P<.05$ ). Index patients had a significantly higher general health perception than all controls with the exception of healthy subjects but showed significantly lower scores for emotional role function than all control groups. Table IV compares SF-36 data between patients after cardiac surgery and all control groups in more detail.

PTSD. Patients who had cardiac surgery showed significantly higher PTSD scores than patients after maxillofacial surgery (PTSD comparison group I), and normal individuals selected for comparison (PTSD comparison group II) (24.4 vs 19.5 vs 11.6, median values, $P<.05)$. Twelve patients $(15 \%)$ from the total sample of 80 undergoing cardiac surgery, 5 patients from comparison group I (major maxillofacial surgery), and none of the normal comparison subjects had PTSD scores of more than 35, indicating a high probability of PTSD ( $\chi^{2}$ test, $\left.P<.001\right)$. When indicators of disease severity (CSS, SAPS II, and TISS [Therapeutic Intervention Scoring System]) and the duration of postoperative ICU treatment were entered as independent variables and PTSD scores as dependent variables into a stepwise regression analysis with backward elimination, the model demonstrated that PTSD scores in the study sample could be predicted from a linear combination of CSS $(\beta=0.391$, $P=.009)$, SAPS II scores $(\beta=0.342, P=.027)$, and the duration of ICU treatment $(\beta=0.363, P=.019)$ 
with an intercept of 20.7 and $r^{2}=0.314$. TISS did not add significantly $(P=.384)$ to the ability of the model to predict PTSD scores and was eliminated from the equation.

Patient satisfaction. Patient satisfaction with 20 different aspects of daily life was high, reaching a summary score of all items of 156 (median value; first quartile 124; third quartile 176; Table II) of a possible maximal value of 200. No statistically significant difference was observed between patients undergoing CABG or AVR $(P>$.219). Patients from both groups were least satisfied with their degree of physical fitness (rated 6 on the 10-point satisfaction scale) and maximally satisfied with their housing and family situation, their degree of independence, and the medical and surgical treatment they had received (rated 9 on the 10point scale). There was a statistically significant correlation between life satisfaction summary scores and mental $(r=0.517, P<.001)$ and physical sum scores $(r$ $=0.492, P<.001)$ of the SF-36 HRQL measurements.

The relationship between PTSD, HRQL, and patient satisfaction. Patients with evidence of PTSD $(\mathrm{n}=12)$ reported significantly lower SF-36 mental summary scores than emotionally healthy subjects (38.3 vs $48.4, P=.004$ ), with no significant difference regarding physical sum scores (34.0 vs $43.9, P=.173$ ). Other SF-36 indicators of social functioning and mental health were also significantly lower in patients with PTSD (social function: 68.8 vs $87.5, P=.017$; vitality: 45 vs $60.0, P=.010$; emotional role function: $0.00 \mathrm{vs}$ $66.7, P=.012$; or mental health: 52.0 vs 78.0 , $P \leq .001)$. When PTSD scores were entered into a multiple regression model with SF-36 mental health sum scores as a dependent variable and clinical severity scores (CSS), simplified acute physiology (SAPS II) scores, and duration of ICU treatment as independent variables, backward elimination reduced the model to PTSD scores. This then explained variations in mental health sum scores $(\beta=-0.310, P<.027$, intercept $=$ 59.0, $\left.r^{2}=0.25\right)$, and all other factors were removed from the model $(P>.319)$. A similar relationship was found with regard to life satisfaction. Patients with PTSD reported significantly lower satisfaction sum scores (121.5, first quartile, 111.8; third quartile 144.8 vs 162.0, first quartile, 131.8; third quartile 180.0, $P=.002)$ than emotionally stable patients; likewise, all other life satisfaction items were rated significantly lower $(P \leq .034)$ with the exception of social support $(P=.265)$, independence $(P=.071)$, marriage/partnership $(P=.297)$, professional, financial, and housing situation $(P \geq .202)$, and the perceived quality of medical treatment $(P=.259)$. When life satisfaction summary scores were entered into a multiple regression model as a dependent variable and indicators of preoperative disease severity (CSS, SAPS II, TISS, and duration of postoperative mechanical ventilation/ICU therapy) and PTSD scores as independent variables, backward elimination removed all indicators of disease severity, and only PTSD scores explained variations in life satisfaction summary scores $\left(\beta=-1.658, r^{2}=0.451, P<.001\right.$, intercept $=179.9)$.

\section{Discussion}

In this study, we identified and contacted a welldefined group of patients after cardiac surgery and ICU treatment and assessed HRQL outcomes, life satisfaction, and the occurrence and intensity of PTSD. When compared with age- and sex-identical healthy control subjects, HRQL in most patients after cardiac surgery in our study sample is characterized by small impairments in both mental and physical dimensions. This demonstrates the importance of using control groups that are comparable with regard to age and sex when measuring HRQL in elderly patients, because age and sex have a great impact on SF-36 scores, ${ }^{4}$ as well as on other instruments used for HRQL evaluation. ${ }^{23}$ On the other hand, there were no significant differences between patients after cardiac surgery and normal control subjects regarding general health perception or chronic pain. Control patients with more severe cardiovascular disease (myocardial infarction $<1$ year, medically treated angina, or heart failure) reported a significantly lower general health assessment, and the occurrence of chronic pain was much higher in patients after a recent myocardial infarction. These findings indicate a relatively high HRQL in our study sample. This result is corroborated by the high degree of life satisfaction reported by our study cohort. This favorable outcome may be explained in part by the low preoperative disease severity in our patients. HRQL studies in patients with more pronounced cardiac disease (eg, CSS $6.3 \pm 0.4$ ) and prolonged postoperative ICU therapy (TISS $=354$ points, mean ICU stay $=9$ days) because of multiple organ dysfunction have demonstrated much greater impairments in physical function, emotional reactions, and energy. ${ }^{24}$ In addition, not all patients from our study who were initially identified completed our questionnaires. It is conceivable that only the most healthy patients or those most satisfied with their operative result responded to our survey, and this could result in a certain degree of selection bias. Therefore, the subgroup of patients with complete data does not necessarily represent the originally identified study cohort. 
However, a subgroup of patients from our sample report significant limitations in psychosocial functioning and pronounced impairments in life satisfaction. These less favorable outcomes were associated with evidence of PTSD in some of these patients. Although this could be a pure correlational association (eg, patients with PTSD may have a bleak outlook on life and a tendency to report a lower HRQL than emotionally healthy individuals), the inverse relationship between PTSD and HRQL has been described in several other studies ${ }^{25}$ that used the same method ${ }^{6}$ and included patients after prolonged ICU treatment. The overall incidence of PTSD found in our study population is nearly identical to the PTSD frequency described in survivors of a myocardial infarction ${ }^{11}$ (without surgical intervention). Furthermore, the dependency of PTSD scores on preoperative indicators of disease severity in our study suggests pre-existing PTSD rather than acquired PTSD during hospitalization, heart surgery, and ICU treatment. An alternative explanation would be that pre-existing mental illness or impairments in social function predispose patients to the development of PTSD and that a lower HRQL is consecutively detected in those patients in whom PTSD develops. Although our method does not allow the definite exclusion of this possibility, pre-existing impairment in social function or low mental health is known to increase the risk for trauma exposure in the community (eg, domestic violence) but does not increase the vulnerability for development of PTSD once a traumatic experience has occurred. ${ }^{26}$ The major determinants for PTSD, however, are the intensity of the stressor, ${ }^{10}$ probably cortisol levels at the time of stress exposure, ${ }^{27}$ and the degree of catecholaminergic activity. ${ }^{28}$

Of considerable importance in the diagnosis of PTSD is the definition and intensity of the stressful event leading to the syndrome, which should be "outside the range of usual human experience" and "markedly distressing to almost every one" (criterion A). ${ }^{10}$ Physical life threats like acute heart disease are examples of such significant stressors, which could be experienced with "intense fear, terror and helplessness," 10,29 features that were probably present in the subgroup of our patients in whom PTSD developed. In any case, when evaluating psychologic outcomes from cardiac surgery, the possibility of (probably) pre-existing PTSD must be taken into account. An effort should be made to identify such patients early and to refer them to adequate treatment. Medical treatment of PTSD may consist of tricyclic antidepressants or monoamine oxidase inhibitors. Psychosocial techniques, such as cognitive-behavioral therapy or stress inoculation training, are effective and may be considered as adjunctive therapy. ${ }^{30}$

In conclusion, this study addresses the increasingly important issue of assessing HRQL outcome and patient satisfaction after heart surgery and demonstrates a high rate of patient contentment and an acceptable degree of physical and social functioning. Impairments in psychosocial function and life satisfaction were found in a subgroup of patients with evidence of PTSD.

\section{REFERENCES}

1. Califf RM, Harrell FE Jr, Lee KL, Rankin JS, Hlatky MA, Mark $\mathrm{DB}$, et al. The evolution of medical and surgical therapy for coronary artery disease: a 15-year perspective [see comments]. JAMA 1989;261:2077-86.

2. Predicting outcome in ICU patients. 2nd European Consensus Conference in Intensive Care Medicine. Intensive Care Med 1994;20:390-7.

3. Katz S. The science of quality of life. J Chronic Dis 1987;40:459-63.

4. Bullinger M, Kirchberger I. SF-36 Fragebogen zum Gesundheitszustand. 1 ed. Göttingen: Hogrefe; 1998.

5. Tian ZM, Miranda DR. Quality of life after intensive care with the sickness impact profile. Intensive Care Med 1995;21:422-8.

6. Schelling G, Stoll C, Haller M, Briegel J, Manert W, Hummel T, et al. Health-related quality of life and post-traumatic stress disorder in survivors of the acute respiratory distress syndrom (ARDS). Crit Care Med 1998;25:651-9.

7. Speziale G, Bilotta F, Ruvolo G, Fattouch K, Marino B. Return to work and quality of life measurement in coronary artery bypass grafting. Eur J Cardiothorac Surg 1996;10:852-8.

8. Roach GW, Kanchuger M, Mangano CM, Newman M, Nussmeier N, Wolman R, et al. Adverse cerebral outcomes after coronary bypass surgery: Multicenter Study of Perioperative Ischemia Research Group and the Ischemia Research and Education Foundation Investigators [see comments]. N Engl J Med 1996;335:1857-63.

9. Horowitz MJ. Stress-response syndromes: a review of posttraumatic stress and adjustment disorders. In: Wilson JP, Raphael B, editors. International handbook of traumatic stress syndromes. New York: Plenum Press; 1993. p. 49-60.

10. American Psychiatric Association. American Psychiatric Association: diagnostic and statistical manual of mental disorders. 4th ed. Washington (DC): American Psychiatric Association; 1994.

11. van Driel RC, Op den Velde W. Myocardial infarction and posttraumatic stress disorder. J Trauma Stress 1995;8:151-9.

12. Higgins TL, Estafanous FG, Loop FD, Beck GJ, Blum JM, Paranandi L. Stratification of morbidity and mortality outcome by preoperative risk factors in coronary artery bypass patients: a clinical severity score [published erratum appears in JAMA 1992;268:1860] [see comments]. JAMA 1992;267:2344-8.

13. Schuster HP, Schuster FP, Ritschel P, Wilts S, Bodmann KF. The ability of the Simplified Acute Physiology Score (SAPS II) to predict outcome in coronary care patients. Intensive Care Med 1997;23:1056-61.

14. Ware JE, Sherbourne CD. The MOS 36-Item Short-Form Health 
Survey (SF-36). I. Conceptual framework and item selection. Med Care 1992;30:473-81.

15. Ware JE, Snow KK, Kosinski M, Gandek B. SF-36 Health Survey Manual and Interpretation Guide. Boston (MA): The Health Institute; 1993.

16. Ware JE, Kosinski M, Keller DS. SF-36 Physical \& Mental Health Summary Scales, a User's Manual. Boston: The Health Institute, New England Medical Center; 1994.

17. Phillips RC, Lansky DJ. Outcomes management in heart valve replacement surgery: early experience [see comments]. J Heart Valve Dis 1992;1:42-50.

18. Chrispin PS, Scotton H, Rogers J, Lloyd D, Ridley SA. Short Form 36 in the intensive care unit: assessment of acceptability, reliability and validity of the questionnaire. Anaesthesia 1997;52:15-23.

19. Dougherty CM, Dewhurst T, Nichol WP, Spertus J. Comparison of three quality of life instruments in stable angina pectoris: Seattle Angina Questionnaire, Short Form Health Survey (SF36), and Quality of Life Index-Cardiac Version III. J Clin Epidemiol 1998;51:569-75.

20. Weisaeth L. Torture of a Norwegian ship's crew: the torture, stress reactions and psychiatric after-effects. Acta Psychiatr Scand Suppl 1989;355:63-72.

21. Stoll C, Kapfhammer HP, Haller H, Briegel J, Krauseneck T, Durst K, et al. Sensitivity and specificity of a screening test to document traumatic experiences and to diagnose post-traumatic stress disorder in patients after intensive care treatment. Intensive Care Med 1999;25:697-704.
22. Altman DG. Multiple regression. In: Altman DG, editor. Practical statistics for medical research. London: Chapman \& Hall; 1991. p. 336-51.

23. Hunt SM, McEwen J, McKenna SP. Perceived health: age and sex comparisons in a community. J Epidemiol Community Health 1984;38:156-60.

24. Nielsen D, Sellgren J, Ricksten SE. Quality of life after cardiac surgery complicated by multiple organ failure [see comments]. Crit Care Med 1997;25:52-7.

25. Warshaw M. Quality of life and dissociation in anxiety disorder patients with histories of trauma or PTSD. Am J Psychiatry 1993;150:1512-6.

26. Breslau N. Traumatic events and PTSD in an urban population of young adults. Arch Gen Psychiatry 1991;48:216-22.

27. Schelling G, Stoll C, Kapfhammer HP, Rothenhausler HB, Krauseneck T, Durst K, et al. The effect of stress doses of hydrocortisone during septic shock on posttraumatic stress disorder and health-related quality of life in survivors. Crit Care Med 1999;27:2678-83.

28. Southwick SM, Bremner JD, Rasmusson A, Morgan CA III, Arnsten A, Charney DS. Role of norepinephrine in the pathophysiology and treatment of posttraumatic stress disorder. Biol Psychiatry 1999;46:1192-204.

29. Wilson JP. The historical evolution of PTSD diagnostic criteria: from Freud to DSM-IV. J Trauma Stress 1994;7:681-8.

30. Davidson JR, Connor KM. Management of posttraumatic stress disorder: diagnostic and therapeutic issues. J Clin Psychiatry 1999;60(Suppl 18):33-8.

\section{Online-www.aats.org}

Now you can get The Journal of Thoracic and Cardiovascular Surgery online. The Journal online brings you faster delivery time, easy searching of current and back issues, links to PubMed, AATS, WTSA, and other important sites, and more. Visit the Journal online today.

\section{Receive tables of contents by e-mail}

To receive the tables of contents by e-mail, sign up through our Web site at http://www.mosby.com/jtcvs. Choose E-mail Notification. Simply type your e-mail address in the box and click the Subscribe button.

Alternatively, you may send an e-mail message to majordomo@mosby.com. Leave the subject line blank and type the following as the body of your message: subscribe jtcvs_toc.

You will receive an e-mail to confirm that you have been added to the mailing list. Note that table of contents e-mails will be sent out when a new issue is posted to the Web site. 